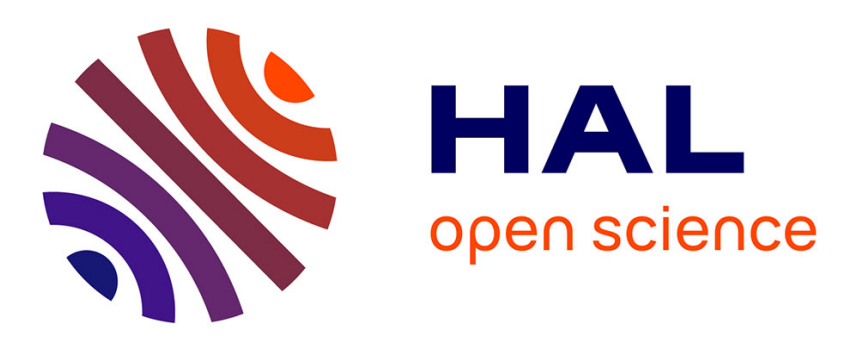

\title{
Emergence of Kelvin-Helmholtz instabilities in shallow mixing layers: An experimental study
}

Sébastien Proust, Céline Berni, V.I. Nikora

\section{To cite this version:}

Sébastien Proust, Céline Berni, V.I. Nikora. Emergence of Kelvin-Helmholtz instabilities in shallow mixing layers: An experimental study. River Flow 2020, Jul 2020, Delft, Netherlands. pp.8. hal03130140

\author{
HAL Id: hal-03130140 \\ https://hal.science/hal-03130140
}

Submitted on 3 Feb 2021

HAL is a multi-disciplinary open access archive for the deposit and dissemination of scientific research documents, whether they are published or not. The documents may come from teaching and research institutions in France or abroad, or from public or private research centers.
L'archive ouverte pluridisciplinaire HAL, est destinée au dépôt et à la diffusion de documents scientifiques de niveau recherche, publiés ou non, émanant des établissements d'enseignement et de recherche français ou étrangers, des laboratoires publics ou privés. 


\title{
Emergence of Kelvin-Helmholtz instabilities in shallow mixing layers: An experimental study
}

\author{
S. Proust \& C. Berni \\ INRAE, Lyon-Villeurbanne, France \\ V.I. Nikora \\ University of Aberdeen, Aberdeen, United Kingdom
}

\begin{abstract}
Free-surface shallow mixing layers behind a splitter plate were studied in a flume of rectangular cross-section consisting of a bed and sidewalls made of glass. The focus is on the effects on the emergence of horizontal Kelvin-Helmholtz-type coherent structures (KHCSs) of vertical flow confinement (i.e., flow depth) and dimensionless velocity shear $\lambda=\left(U_{x 2}-\right.$ $\left.U_{x 1}\right) /\left(U_{x 2}+U_{x 1}\right)$, where $U_{x 1}$ and $U_{x 2}$ are two flow velocities characterizing the low-speed stream and high-speed stream, respectively. Two flow depths were tested, with the $\lambda$-value at the flume entrance varying between 0.1 to 0.8 , with a threshold value $\lambda_{t}=0.3$ needed for the emergence of KHCSs in compound open-channel flows being inside this range. This paper reports new data that provide a better insight in the interplay between the constraining effect of flow depth, damping effect of three-dimensional bed-induced turbulence, and triggering effect of dimensionless shear on the formation of KHCSs.
\end{abstract}

Keywords: Shallow shear flows; coherent structures; shear layer turbulence

\section{INTRODUCTION}

It has been recently shown that the emergence and development of Kelvin-Helmholtz-type coherent structures (KHCSs) in streamwise-depth-uniform and non-uniform flows in compound open channels (Proust et al, 2017; Proust \& Nikora, 2020) are driven by the dimensionless velocity shear $\lambda=\left(U_{x 2}-U_{x 1}\right) /\left(U_{x 2}+U_{x 1}\right)$, where $U_{x 2}$ and $U_{x 1}$ are the time-averaged streamwise velocities outside the mixing layers within the high-speed stream and low-speed stream, respectively. KHCSs can emerge once $\lambda$ exceeds a critical value $\left(\lambda_{t}=0.3\right)$ above which KHCSs length-scales increase with the shear (Proust \& Nikora, 2020), irrespective of the vertical flow confinement. It is important to note that $\lambda \geq 0.3$ is a necessary condition but not a sufficient one, as observed by Proust et al (2017). KHCS emergence also requires the presence of an inflection point in the time-averaged streamwise velocity profile so that Rayleigh's criterion is fulfilled (e.g., Huerre \& Rossi, 1998).

On the other hand, in the case of shallow mixing layers in non-compound open-channels with a rectangular cross-section, the experiments of e.g., Chu \& Babarutsi (1988) and Uijttewaal \& Booij (2000) have evidenced the constraining effects of vertical flow confinement and bed-friction on the development of large coherent structures that may populate shallow mixing layers. The present study, conducted in a laboratory flume with a rectangular cross-section, is an attempt to get a better insight in the interplay between the constraining effect of the flow depth, the damping effect of three-dimensional bed-induced turbulence, and the triggering effect of dimensionless shear on the formation of KHCSs. As an initial step, a simpler case of hydraulically smooth bed and sidewalls is considered. 


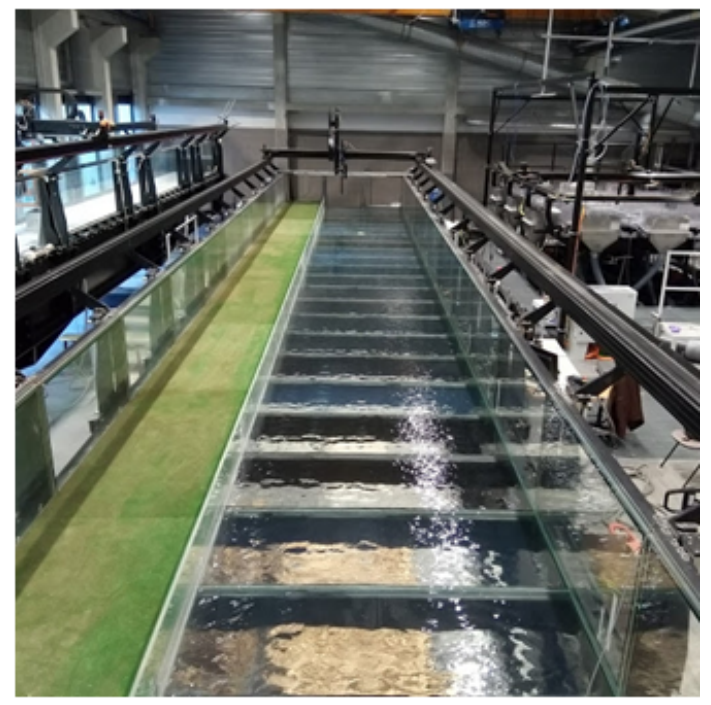

Figure 1. Open-channel flume located in the Hydraulics and Hydro-morphology Laboratory (HHLab) at INRAE, Lyon-Villeurbanne. Experiments with a working length $=18 \mathrm{~m}$ and a working width $=2 \mathrm{~m}$ (right-hand $2 / 3$ of the total flume width with bed and sidewalls made of glass).

Table 1. Flow conditions of the test cases: mean flow depth (averaged across and along the flow) $D_{x, y}$; total inflow discharge $Q$ and left-hand and right-hand inflow discharges $Q_{2}$ and $Q_{1}$; timeaveraged streamwise velocities $U_{x 2}$ and $U_{x 1}$, velocity $U_{x, m}=$ $\left(U_{x 2}+U_{x 1}\right) / 2$, dimensionless velocity shear $\lambda$, Froude numbers $F r_{2}=U_{x 2} / \sqrt{g D_{x, y}}$ and $F r_{1}=U_{x 1} / \sqrt{g D_{x, y}}$ at $x=2.4 \mathrm{~m}$.

\begin{tabular}{|c|c|c|c|c|c|c|c|c|c|c|}
\hline \multirow[b]{2}{*}{ Cases } & \multirow[b]{2}{*}{$\begin{array}{c}D_{x, y} \\
{[\mathrm{~mm}]}\end{array}$} & \multicolumn{3}{|c|}{ Inflow discharges } & \multicolumn{6}{|c|}{ Flow parameters at $x=2.4 \mathrm{~m}$} \\
\hline & & $\begin{array}{c}Q \\
{\left[1 \mathrm{~s}^{-1}\right]}\end{array}$ & $\begin{array}{c}Q_{1} \\
{\left[1 \mathrm{~s}^{-1}\right]}\end{array}$ & $\begin{array}{c}Q_{2} \\
{\left[1 \mathrm{~s}^{-1}\right]}\end{array}$ & $\begin{array}{c}U_{x 1} \\
{\left[\mathrm{~cm} \mathrm{~s}^{-1}\right]}\end{array}$ & $\begin{array}{c}U_{x 2} \\
{\left[\mathrm{~cm} \mathrm{~s}^{-1}\right]}\end{array}$ & $\begin{array}{c}U_{x, m} \\
{\left[\mathrm{~cm} \mathrm{~s}^{-1}\right]}\end{array}$ & $\lambda$ & $\mathrm{Fr}_{1}$ & $\mathrm{Fr}_{2}$ \\
\hline $05-55$ & 51.6 & 60 & 5 & 55 & 14.8 & 119.1 & 67.0 & 0.75 & 0.2 & 1.7 \\
\hline $15-45$ & 56.8 & 60 & 15 & 45 & 31.6 & 81.9 & 56.8 & 0.44 & 0.4 & 1.1 \\
\hline $20-40$ & 56.0 & 60 & 20 & 40 & 38.4 & 72.1 & 55.3 & 0.30 & 0.5 & 1.0 \\
\hline $25-35$ & 56.9 & 60 & 25 & 35 & 46.4 & 61.1 & 53.8 & 0.14 & 0.6 & 0.8 \\
\hline $30-30$ & 59.0 & 60 & 30 & 30 & 53.6 & 50.8 & 52.2 & -0.03 & 0.7 & 0.7 \\
\hline $07-23$ & 38.4 & 30 & 7 & 23 & 22.7 & 58.3 & 40.5 & 0.44 & 0.4 & 0.9 \\
\hline $09-21$ & 38.9 & 30 & 9 & 21 & 27.4 & 54.3 & 40.9 & 0.33 & 0.4 & 0.9 \\
\hline $15-15$ & 40.1 & 30 & 15 & 15 & 40.2 & 38.8 & 39.5 & -0.02 & 0.6 & 0.6 \\
\hline
\end{tabular}
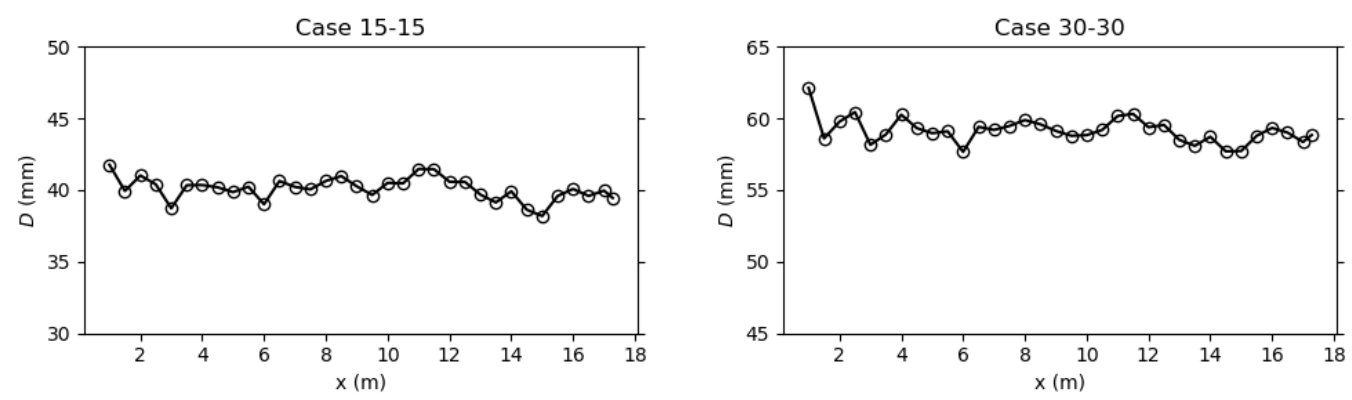

Figure 2. Streamwise profiles of local flow depth $D$ at transverse position $y=1 \mathrm{~m}$ for the two uniform flow cases 15-15 and 30-30. 


\section{EXPERIMENTS}

The experiments were conducted in an $18 \mathrm{~m}$ long and $2 \mathrm{~m}$ wide open channel flume with a rectangular cross-section composed of a bed and sidewalls, both of which are made of glass (Figure 1). The flume is equipped with two independent inlet tanks (1.7 $\mathrm{m}$ long and $1 \mathrm{~m}$ wide each). Each tank is supplied with water through a tower with a constant water level reservoir. The flow rate in the left-hand tank $\left(Q_{2}\right)$ and the flow rate in the right-hand tank $\left(Q_{1}\right)$ are monitored with two independent flow meters. A Cartesian right-handed coordinate system is used in which $x$-axis is in the longitudinal direction parallel to the flume bottom, $y$-axis is in the spanwise direction, and $z$-axis is in the vertical direction (perpendicular to the flume bed). The system origin is defined as: $x=0$ at the outlet of the inlet tanks; $y=0$ at the right-hand sidewall; $z=0$ at the channel bottom. The flow partition is maintained until $x=0.75 \mathrm{~m}$ by a vertical splitter plate.

The flow conditions of the test cases are presented in Table 1. Each test case is identified by its values of $Q_{1}$ and $Q_{2}$, e.g. case $15-45$ corresponds to $Q_{1}=151 \mathrm{~s}^{-1}$ and $Q_{2}=451 \mathrm{~s}^{-1}$. Two total flow rates $Q$ were used $\left(60\right.$ and $301 \mathrm{~s} \mathrm{~s}^{-1}$ ) to vary the vertical flow confinement. Given a $Q-$ value, the flow partition between the two inlet tanks was varied: five cases were investigated for $Q=60$ $1 \mathrm{~s}^{-1}$ and three cases for $Q=301 \mathrm{~s}^{-1}$. The two flow cases with equal discharges $Q_{1}$ and $Q_{2}(15$ and $15 \mathrm{l} \mathrm{s}^{-1}$ or 30 and $30 \mathrm{l} \mathrm{s}^{-1}$ ) will serve as reference flow conditions.

Water surface elevation $Z$ and bed elevation $Z_{b}$ were measured using an ultrasonic probe (Baumer UNDK) for $180 \mathrm{~s}$ at $50 \mathrm{~Hz}$ at each measuring point, from $x=1 \mathrm{~m}$ to $17.3 \mathrm{~m}$ at lateral positions $y=0.5 \mathrm{~m}, 1 \mathrm{~m}$, and $1.5 \mathrm{~m}$ (three longitudinal transects). A spatially averaged flow depth $D_{x, y}$ is then computed from the data of local flow depth $D=Z-Z_{b}$. For the two uniform flow cases 30-30 and 15-15, the mean flow depth (averaged across and along the flow) was found to be $D_{x, y}=59.0$ and $40.1 \mathrm{~mm}$, respectively. Figure 2 shows a longitudinal profile of flow depth $D$ for these flow cases at $y=1 \mathrm{~m}$.

Velocity was measured using an Acoustic Doppler Velocimeter (3-D Nortek Vectrino+) with a side looking probe (sampling volume $5 \mathrm{~cm}$ away from the probe). At each measuring point, the three instantaneous velocity components $u_{x}, u_{y}, u_{z}$ were recorded at $100 \mathrm{~Hz}$ for $300 \mathrm{~s}$. Transverse profiles of velocity were measured at downstream positions $x=2.4,4.4,6.4$ (for case 15-45 only), $8.4,12.4$, and $16.4 \mathrm{~m}$, with a spatial interval of $5 \mathrm{~cm}$ in the spanwise direction, and at elevation $z$ $=30 \mathrm{~mm}$ for $Q=601 \mathrm{~s}^{-1}$ and $z=19 \mathrm{~mm}$ for $Q=301 \mathrm{~s}^{-1}$ (i.e. at mid water depth of the reference uniform cases $15-15$ and 30-30).

\section{EXPERIMENTAL RESULTS}

\subsection{Time-averaged velocity and turbulence statistics}

Spanwise distributions of time-averaged streamwise velocity $U_{x}$, transverse Reynolds shear stress $-\rho \overline{u_{x}^{\prime} u_{y}^{\prime}}$, and transverse turbulence intensity $\overline{\rho u_{y}^{\prime 2}}$ are shown in Figure 3 for cases 15-45 and 25-35. For these two cases, vertical flow confinement is similar $\left(D_{x, y}=56.8\right.$ and $56.9 \mathrm{~mm}$, respectively, Table 1) and inflection points in $U_{x}$-distributions are observed for both cases at all $x$-positions.

The velocity measurements indicate that turbulence statistics in the upstream half-flume are noticeably higher for $15-45$ than for $25-45$ (see the data from $x=2.4$ to $8.4 \mathrm{~m}$ ). This is due to the higher values of destabilizing shear $U_{x 2}-U_{x 1}$ (Huerre \& Rossi, 1998) for the former case, where $U_{x 2}$ and $U_{x 1}$ are the time-averaged streamwise velocities outside the mixing layers within the high-speed stream and low-speed stream, respectively. Note that, here, $U_{x 1}$ is the velocity averaged across the plateau of $U_{x}(y)$ on the low speed stream side when a plateau can be observed or is the minimum value of $U_{x}$ on the same side; and $U_{x 2}$ is the velocity averaged across the plateau of $U_{x}(y)$ on the high speed stream side when a plateau can be observed or is the maximum value of $U_{x}$ on the same side.

\subsection{Effect of the dimensionless velocity shear $\lambda$}

Similarly to Proust et al (2017) and Proust \& Nikora (2020), we have studied the effect of the dimensionless velocity shear $\lambda=\left(U_{x 2}-U_{x 1}\right) /\left(U_{x 2}+U_{x 1}\right)$ (Brown \& Roshko, 1974) on the planform shear layer turbulence. The longitudinal profiles of $\lambda$ for all cases are shown in Figure 4. In the present paper, we have focused on the effect of $\lambda$ on the peak values of turbulence statistics 
Case $15-45$

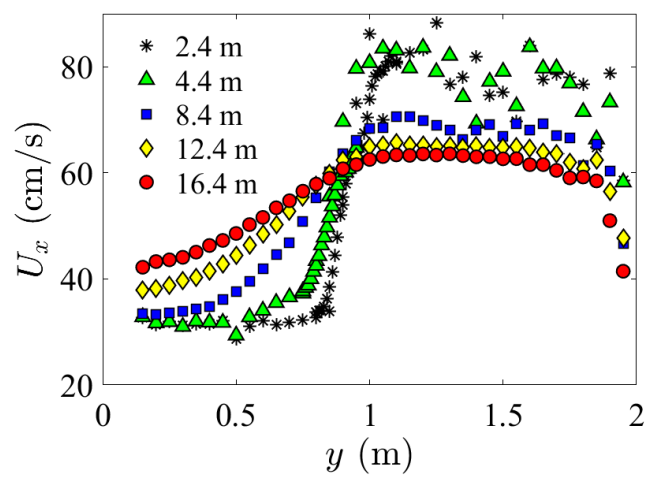

Case 15-45

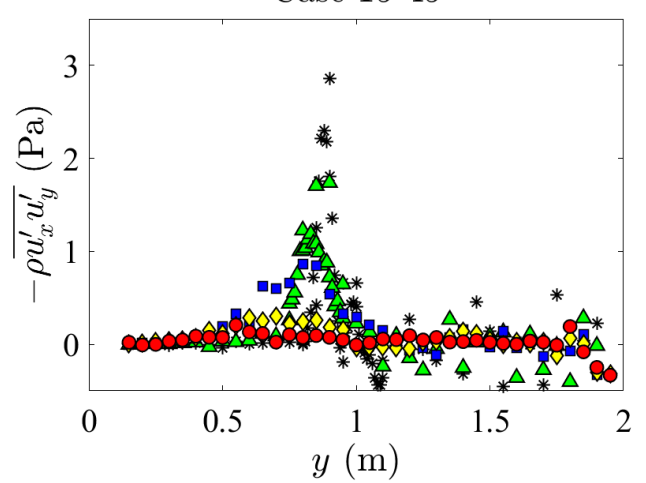

Case 15-45

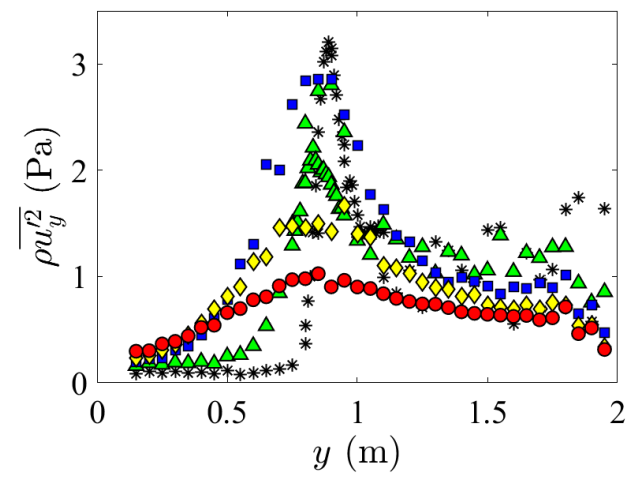

Case 15-45

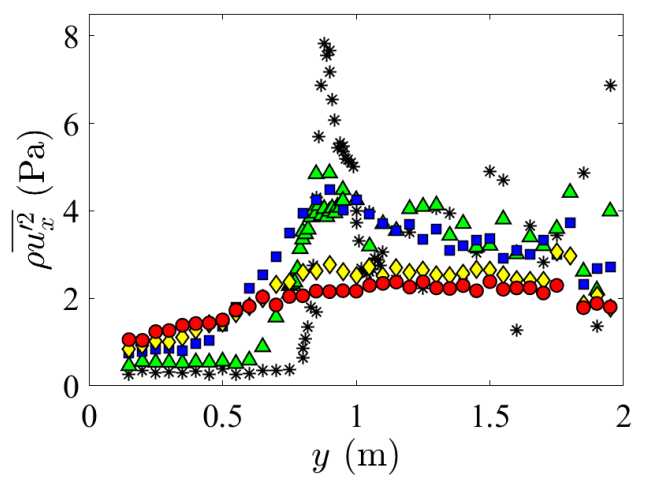

Case 25-35

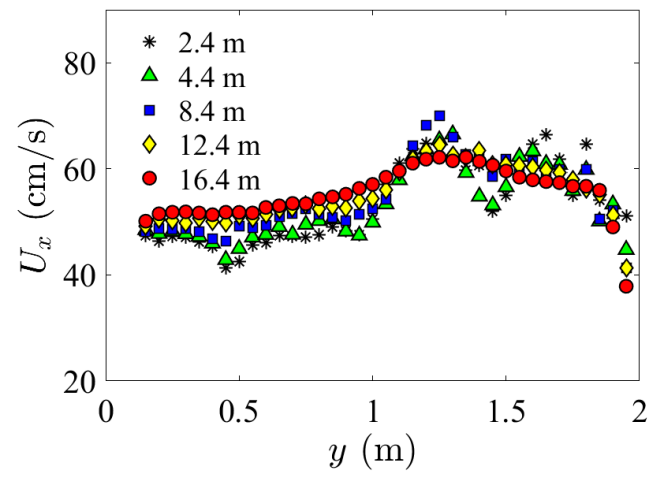

Case 25-35

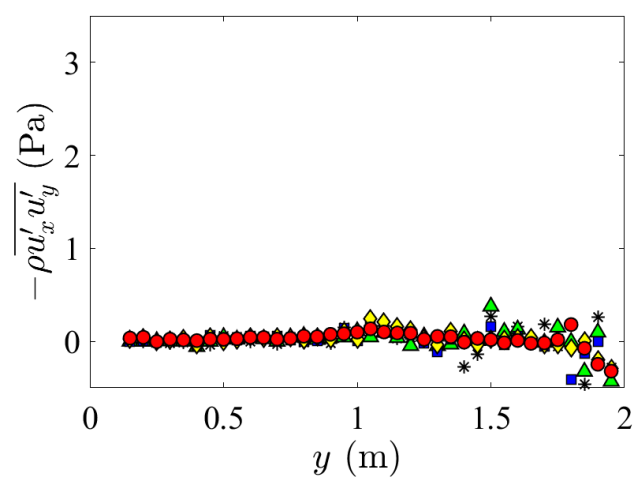

Case 25-35

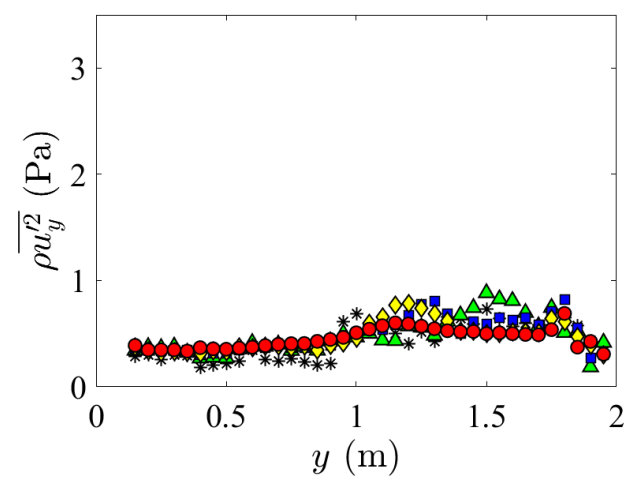

Case 25-35

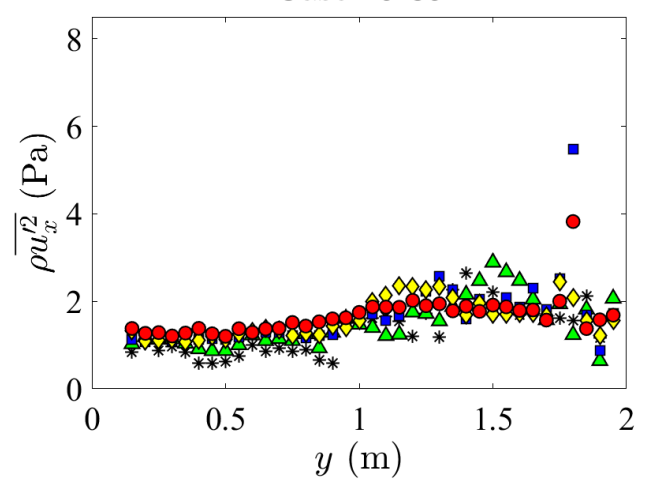

Figure 3. Spanwise distributions of time-averaged streamwise velocity $U_{x}$, transverse Reynolds shear stress $-\rho \overline{u_{x}^{\prime} u_{y}^{\prime}}$, transverse normal turbulent stress $\rho \overline{u_{y}^{\prime 2}}$, and streamwise normal turbulent stress $\rho \overline{u_{x}^{\prime 2}}$ for two cases with total flow rate $Q=601 \mathrm{~s}^{-1}$

across the channel at a given longitudinal position $x$. The longitudinal profiles of the maximum transverse Reynolds shear stress (denoted as $\operatorname{Max}\left(-\rho \overline{u_{x}^{\prime} u_{y}^{\prime}}\right)$ ) and maximum transverse normal 


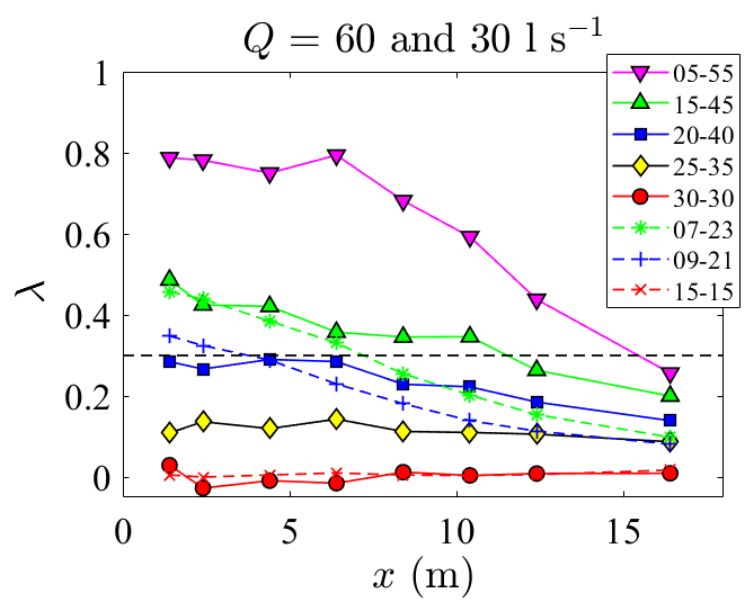

Figure 4. Streamwise profiles of the dimensionless velocity shear $\lambda=\left(U_{x 2}-U_{x 1}\right) /\left(U_{x 2}+U_{x 1}\right)$ for all cases, at elevation $z=30 \mathrm{~mm}$ for $Q=601 \mathrm{~s} \mathrm{~s}^{-1}$ and $z=19 \mathrm{~mm}$ for $Q=301 \mathrm{~s}^{-1}$.

turbulent stress $\left(\operatorname{Max}\left(\rho \overline{u_{y}^{\prime 2}}\right)\right)$ are shown in Figures 5(a-b) and Figures 5(c-d), respectively. At a given $x$-position, the peak Reynolds shear stress is also plotted as a function of the local value of $\lambda$ in Figures 5e-f.

Figures 5e-f highlight that, for the moderately sheared flows (cases 7-23, 9-21, 20-40, and 1545 , with $\lambda=0.3$ to 0.4 at $x=2.4 \mathrm{~m}$, Table 1, Figure 4), the peak Reynolds shear stress increases with $\lambda$, and additionally, a sharp rise in the shear stress values is observed when $\lambda$ approximately exceeds 0.3 , irrespective of the flow depth. Note that the same result was observed by Proust et al (2017) for 25 flow cases in two compound open-channel flumes with a wide range of flow depths.

The abrupt change in shear stress is related to a change in the turbulence structure. This is shown in Figure 6 where power density $P_{y y}$ of transverse velocity fluctuations $u_{y}^{\prime}$ is plotted as a function of signal frequency $f$. The high values of Reynolds stress are always associated with the presence of large coherent structures (KHCSs), whose spectral signature is a sharp bump in the medium range of frequency $f$ with a -3 slope on the right-hand side of the bump. For instance, for case 7-23, the two high values of $-\rho \overline{u_{x}^{\prime} u_{y}^{\prime}}$ in Figure 5e are related to the two sharp bumps in Figure 6 (top left plot, data with $\lambda=0.44$ and 0.39). Similar results are obtained for case 15-45 (see the data in Figure 5f with $\lambda>0.3$, and the data in Figure 6 with $\lambda=0.44,0.43$, and 0.35).

When the flow is weakly sheared (case 25-35 with $\lambda=0.14$ at $x=2.4 \mathrm{~m}$, Table 1, Figure 4) or non-sheared (uniform flow case 15-15), the absence of bump in the power density spectra reflects the absence of KHCSs (Figure 6), resulting in very low shear stress values (Figures 5a,b,e,f).

Lastly, case 5-55 that is highly sheared (Table 1, Figure 5), and whose Froude number $\mathrm{Fr}_{2}$ reaches 1.7, appears to have a specific behavior when focusing on Figure 5f. The sharp change in Reynolds stress occurs at $\lambda=0.55$ (instead of 0.3 for the moderately flow cases). This may be due to the highest values of velocity $U_{x, m}=\left(U_{x 2}+U_{x 1}\right) / 2$ (usually considered as an approximation of the convection velocity of eddies) and also to a Froude number effect on the KHCSs in the upstream half-flume with a lateral juxtaposition of a marked supercritical flow $\left(F r_{2}=1.7\right)$ and a marked subcritical flow $\left(F r_{1}=0.2\right)$.

\subsection{Effect of flow confinement and bed-induced turbulence}

Figure 6 demonstrates that shallowness has no effect on the emergence of large planform coherent structures. For instance, the flow depth $D_{x, y}$ equals to $38.4 \mathrm{~mm}$ for case $07-23$ and to $40.1 \mathrm{~mm}$ for case 15-15 (Table 1), while the signature of KHCSs is present for the shallower flow (07-23) and absent for the deeper flow (15-15). A similar result is obtained when comparing case 15-45 and case 25-35 (values of $D_{x, y}$ in Table 1, Figure 6). Figures 3 and 6 additionally show that turbulence statistics significantly vary from one case to another for a fixed $z$-elevation and flow confinement, reflecting that flow confinement is not the driving parameter in forming the turbulence structure.

In contrast, flow confinement appears to accelerate the decay in the destabilizing shear $U_{x 2}-$ $U_{x 1}$ (not shown here) and in dimensionless velocity shear $\lambda$ along the longitudinal direction 
(a) $Q=30 \mathrm{~L} / \mathrm{s}$

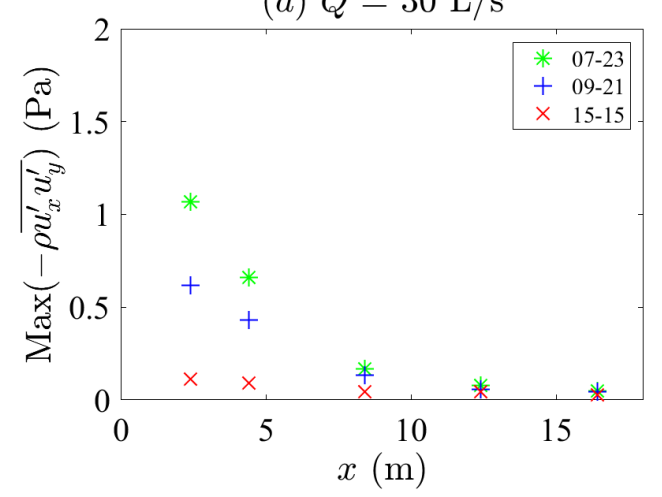

(c) $Q=30 \mathrm{~L} / \mathrm{s}$

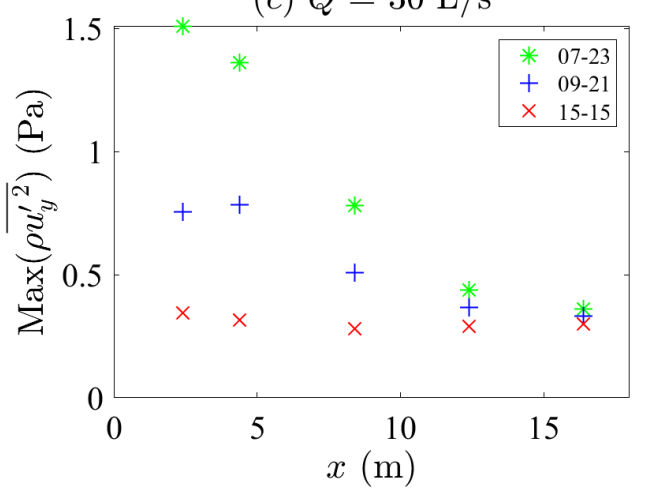

(e) $Q=30 \mathrm{~L} / \mathrm{s}$

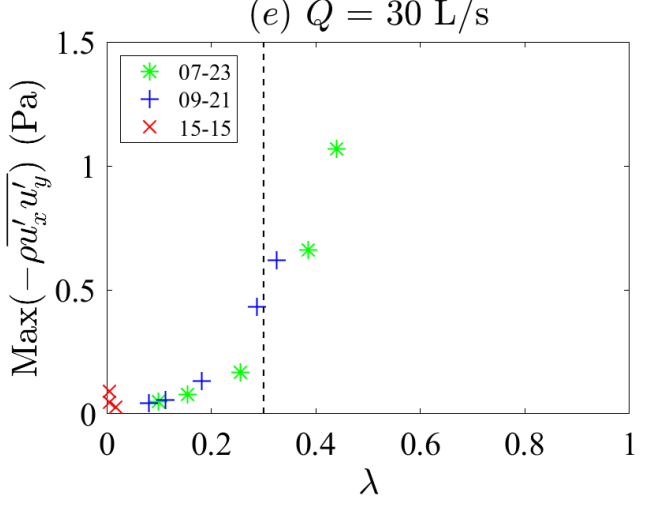

(b) $Q=60 \mathrm{~L} / \mathrm{s}$

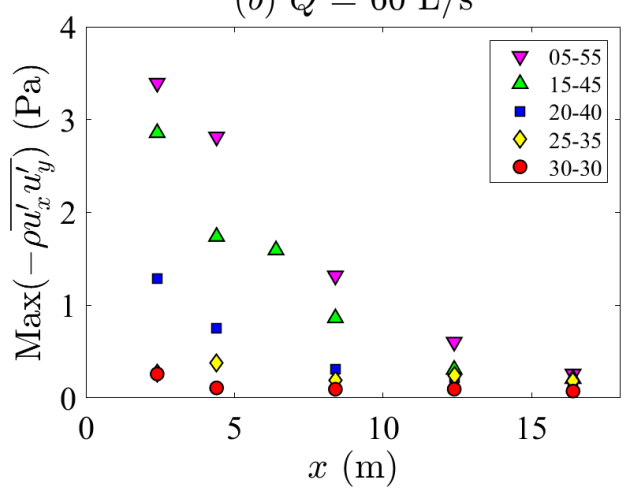

(d) $Q=60 \mathrm{~L} / \mathrm{s}$
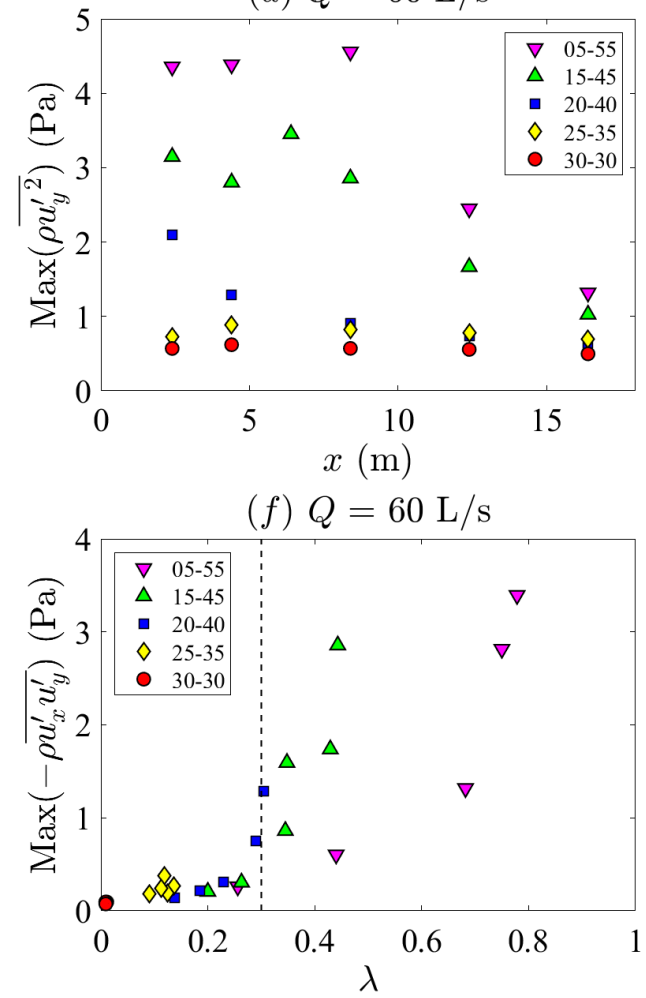

Figure 5. Streamwise profiles of the maximum values across the channel of the transverse Reynolds shear stress $-\rho \overline{u_{x}^{\prime} u_{y}^{\prime}}(\mathrm{a}-\mathrm{b})$ and transverse normal turbulent stress $\rho \overline{u_{y}^{\prime 2}}(\mathrm{c}-\mathrm{d})$, and maximum Reynolds shear stress as a function of local dimensionless velocity shear $\lambda$ (e-f). Measurements are taken at $z=30 \mathrm{~mm}$ for 60 $1 \mathrm{~s}^{-1}$ and at $z=19 \mathrm{~mm}$ for $301 \mathrm{~s}^{-1}$.

(Figure 4, compare cases $07-23$ and 15-45 with the same $\lambda$-value at $x=2.4 \mathrm{~m}$ on the one hand, or cases 20-40 and 9-21 on the other hand).

Regarding the potential damping effect of bed-induced turbulence on planform transverse motions (Chu \& Babarutsi 1988, Uijttewaal \& Booij 2000), some present data do not support this previous result reported in the literature. For instance, let us focus on the distributions of $\rho \overline{u_{x}^{\prime 2}}$ for both cases $25-35$ and $15-45$ at $x=8.4 \mathrm{~m}$ (for which $\lambda=0.12$ and 0.35 , respectively) outside the mixing layer $(y<0.3 \mathrm{~m})$. We can see that $\rho \overline{u_{x}^{\prime 2}} \approx 1$ Pa for both cases. As quantity $\overline{u_{x}^{\prime 2}}$ in this flow region only reflects bed-induced-turbulence intensity, we can state that this intensity is the same outside the mixing layer on the right-hand side of the flow. However, the distributions of $\overline{u_{y}^{\prime 2}}$ and Reynolds shear stress at $x=8.4 \mathrm{~m}$ (Figure 5) and the spectra (Figure $6, \lambda=0.35$ for case 15-45 and $\lambda=0.12$ for case 25-35) both highlight the presence of KHCSs in case 15-45 but not in case $25-35$. 

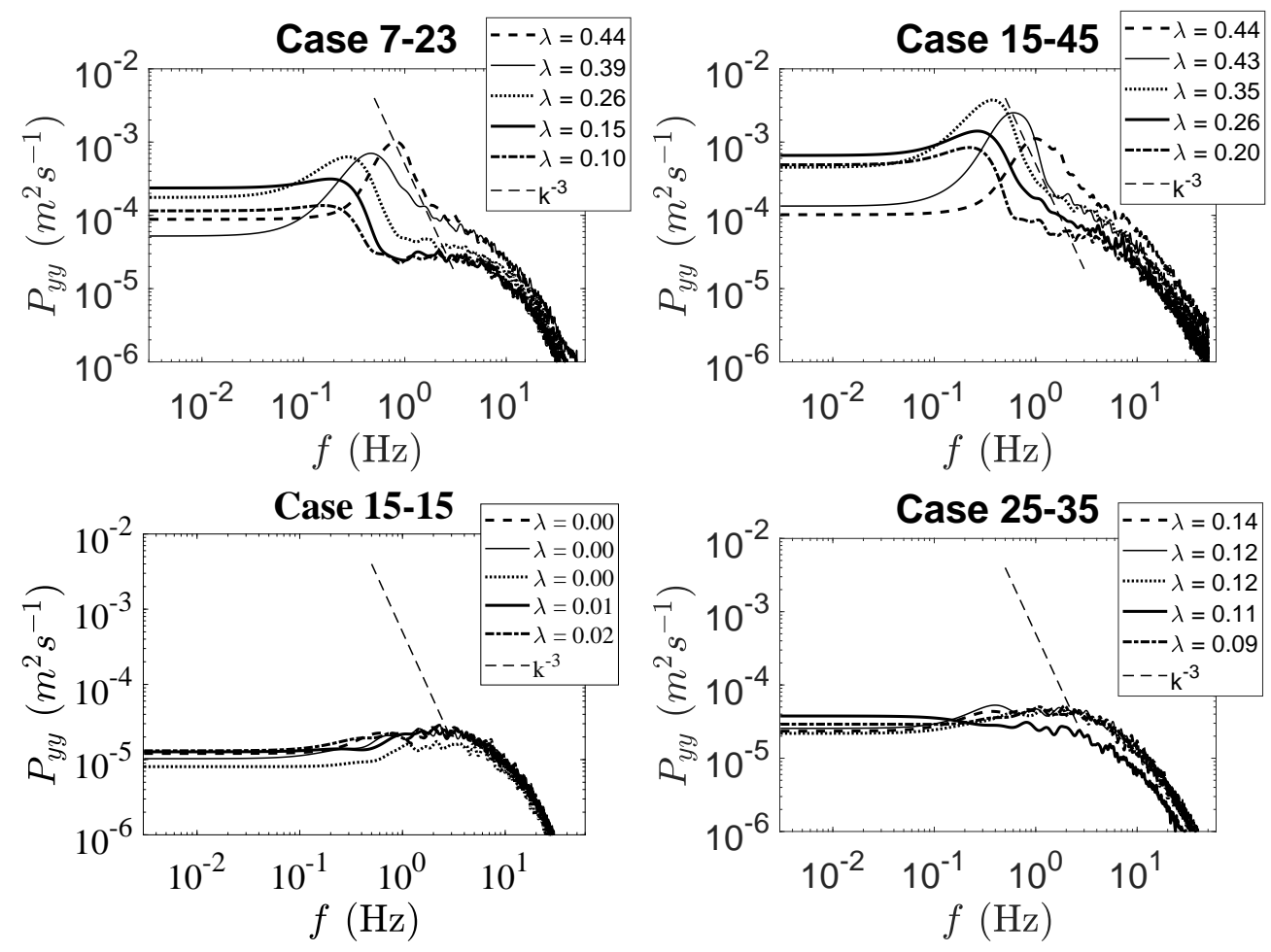

Figure 6. Power density $P_{y y}$ of transverse velocity fluctuations $u_{y}^{\prime}$ as a function of signal frequency $f$. Measurements are taken at $y=0.9 \mathrm{~m}$ and $z=19 \mathrm{~mm}$ for cases $15-15$ and $7-23$, and at $z=30 \mathrm{~mm}$ for cases $15-45$ and 25-35.

\section{CONCLUSIONS}

Free-surface shallow mixing layers behind a splitter plate were studied in $18 \mathrm{~m}$ long and $2 \mathrm{~m}$ wide laboratory channel with a glass bed. The focus was on assessing the effects of vertical flow confinement (i.e., flow depth) and dimensionless velocity shear $\lambda=\left(U_{x 2}-U_{x 1}\right) /\left(U_{x 2}+U_{x 1}\right)$ on the emergence of horizontal Kelvin-Helmholtz-type coherent structures (KHCSs). Two flow depths were tested, with the $\lambda$-value at the flume entrance varying between 0.1 to 0.8 . It was found that the emergence and development of KHCSs was primarily driven by velocity shear $\lambda$, irrespective of flow depth. Same result holds for turbulence statistics. In addition, the threshold value $\lambda_{t}=0.3$ needed for the emergence of KHCSs in compound open-channel flows, appears to be also valid in non-compound channels with a rectangular cross-section. The results also showed that three-dimensional bed-induced turbulence had very little impact on the large transverse turbulent motions. Some two-point velocity measurements (to estimate KHCSs length-scales) will be conducted to confirm this preliminary results.

\section{REFERENCES}

Brown, G. L. \& Roshko, A. (1974). On density effects and large structure in turbulent mixing layers. $J$. Fluid Mech. 64(part 4): 775-816.

Chu, V. H. \& Babarutsi, S. 1988. Confinement and bed-friction effects in shallow turbulent mixing layers. J. Hydraul. Eng. 114(10): 1257-1274.

Huerre, P. \& Rossi, M. 1998. Hydrodynamic instabilities in open flows. In C. Godrèche \& P. Manneville (eds), Hydrodynamics and Nonlinear Instabilities : 81-294. Cambridge University Press.

Proust, S., Fernandes, J. N., Leal, J. B., Rivière, N. \& Peltier, Y. 2017. Mixing layer and coherent structures in compound channel flows: effects of transverse flow, velocity ratio and vertical confinement. Water Resour. Res. 53(4): 3387-3406.

Proust, S. \& Nikora, V. I. 2020. Compound open-channel flows: effects of transverse currents on the flow structure. J. Fluid Mech. 885(A24): 1-38. https://doi.org/10.1017/jfm.2019.973.

Uijttewaal, W. S. J. \& Booij, R. 2000. Effects of shallowness on the development of free-surface mixing layers. Phys. fluids. 12(2): 392-420. 